\title{
Acoustics of historic spaces as a form of intangible cultural heritage
}

\author{
Pavol Brezina*
}

\section{The current state of research}

Archaeological interest in the study of the acoustics of important historic buildings is currently gaining in importance, and there are several areas where research is conducted. Among these I include music archaeology, archaeology of sound, archaeomusicology and archaeoacoustics (Watson \& Keating 1999; Scarre \& Lawson 2006; Knight 2010: 1). Research on acoustic space can, in principle, be divided into two types of project: the measurement of acoustic parameters and the storage of acoustics as audio heritage.

Beranek (1996) provides definitions of the basic parameters of acoustic space that are significant for music and the spoken word. Based on Beranek's methodology, Acoustics of music spaces in the Czech Republic provides one of the most comprehensive acoustic studies of historic spaces intended for music production (Vondrášek et al. 2008, 2010a \& b, 2011). On the other hand, Gerzon (1975) was the first to dedicate himself to options of the acoustic storage of musical spaces, and has laid the foundations for many important findings in the field (Savioja et al. 1999; Ben-Hador \& Neoran 2004).

There are several reasons why acoustic parameters should be examined and stored. One is that any of the world's acoustically interesting spaces could be destroyed or damaged in the future due to accidents or natural disasters. Acoustical measurements and data archiving are therefore of great importance, as the following quotation shows: "When the famous and renowned Gran Teatro La Fenice in Venice burned during the night of 29 January 1996, one of the best sounding opera houses in the world suddenly disappeared. Its sonic behaviour, however, was at least partially saved, because several acoustical measurements had been performed just two months before" (Farina \& Ayalon 2003: 1). Another important reason is the creation of acoustic models for the purpose of their use in post-production studies, in order to get the truest sound display of various important spaces, such as theatres, opera houses, churches and cathedrals. There are two basic methods for creating models-impulse response and virtual space simulation. For the impulse response method, important findings were brought to the fore by Ben-Hador \& Neoran (2004) by describing a comprehensive method of detecting space, even for multi-channel sound. The fact that this method has its place in archaeological research is also corroborated by Murphy's study, which provides concrete results of the measurements of several important buildings in England (Murphy 2005).

A more exigent and complex method for creating acoustic models is the virtual simulation of space. This requires the implementation of real acoustic measurements whose values are

Constantine the Philosopher University, Tr. A. Hlinku 1, SK-94974, Nitra, Slovakia (Email: pbrezina@ukf.sk) 
subsequently processed by a computer program able to simulate the acoustic environment on the basis of entered data. This method also requires a detailed knowledge of the materials from which the building was constructed, including interior specifications. Many aspects of interior equipment affecting the acoustic space were described by Marcus Vitruvius Pollio (The ten books on architecture; Morris 1960), and can be utilised in the investigation of Vitruvian architectural acoustics.

One of the complex projects dealing with the acoustic archiving of important historical spaces is the ERATO project, designed within the Fifth Framework INCO-MED Programme. Haddad (2008: 1) states that the preservation and reconstruction of ancient theatre acoustics is the main point of the ERATO project, and he uses for this purpose a virtual simulation of acoustics and auralisation by way of computer programs (Haddad 2008: 9). Another project within the Fifth Framework INCO-MED Programme is Conservation of the Acoustical Heritage by the Revival and Identification of Sinan's Mosques Acoustics (CAHRISMA). It focuses on the preservation and use of the acoustic cultural heritage of the mosques built by sixteenth-century Ottoman architect Mimar Sinan (Karabiber 2002). Acoustic space simulation is again realised by the virtual simulation method. Some of the projects which have similarly tried to preserve acoustic models are mentioned in Murphy's study (Murphy 2006: 226), namely The York Renaissance Project and A Sense of Place (YRP n.d.)

The common denominator of these projects is archiving and demonstrating the acoustic properties of significant historic buildings, but none of them offers acoustic models to the general public for practical use. In the better cases, they simply provide information about the measured values. At the same time, the focus of existing projects is too narrow, focusing only on local historic monuments. They lack a global dimension and possible mutual cooperation. The fact is that challenging research in the field of acoustics is viable in most cases only thanks to the funds of grant programmes. Preserving the acoustics of historic buildings will have importance, in my opinion, only when it is practised internationally and according to certain predetermined criteria. I therefore propose a methodology for measuring and storing the acoustic space of significant cultural monuments as a basis for further discussion in this area.

\section{A comprehensive acoustic data storage solution as intangible cultural heritage}

\section{Acoustic space measurement methodology}

Every historic space is unique in terms of architecture, location and acoustics. The cornerstone of acoustic space measurements should be the standard STN EN ISO 3382-1 Acoustics. Measurement of room acoustic parameters. Part 1: performance spaces (SUTN 2010). This standard sets out a number of parameters by which it is possible to determine the quality of the characteristics of acoustic space in terms of music and spoken word perception. Each acoustic space measurement should include the following basic parameters while taking into account other parameters of the standard, especially when examining specific spaces:

(C) Antiquity Publications Ltd. 
- reverberation time measured in seconds is the time needed for the average energy density in the space to decay by $20 \mathrm{~dB}\left(\mathrm{~T}_{20}\right)$ or by $30 \mathrm{~dB}\left(\mathrm{~T}_{30}\right)$ after switching the sound source off. It is measured in seconds for octave and one-third octave bands;

- early decay time (EDT) is a reverberation time derived from the initial $10 \mathrm{~dB}$ of decay. It is also a figure that best represents the subjective perception of reverberation time. It is measured in seconds, most often for an octave band;

- early to late sound index (C80) is the data defining the so-called degree of sound clarity. It is given by the ratio between the energy arriving within 80 milliseconds and the energy arriving after 80 milliseconds. For the spoken word, it is necessary to use the index with a shorter period of 50 milliseconds (C50). Vondrášek \& Antek show the following values and associated degree of clarity for each of the musical genres (Vondrášek \& Antek 2005: 10; Table 1):

Table 1. Distribution of clarity range values.

\begin{tabular}{ll}
\hline Decibels & Clarity range \\
\hline $0 \pm 2 \mathrm{~dB}$ & Ideal for organ music and a slower tempo. \\
$2 \pm 2 \mathrm{~dB}$ & Ideal for string instruments and a faster tempo. Also suitable for choral singing. \\
$4 \pm 2 \mathrm{~dB}$ & Ideal for psalteries and a faster tempo. Suitable for folk and light pop music. \\
$6 \pm 2 \mathrm{~dB}$ & Ideal for percussion instruments, modern and contemporary music. \\
\hline
\end{tabular}

- the centre of impulse response in milliseconds $\left(T_{s}\right)$ is closely related to the C80 value and represents the spatial perception and music or spoken word clarity;

- interaural cross-correlation coefficient (IACC) is most frequently stated in the form of IACC $_{\mathrm{E}}$ (early reflections), and the value $\left(1-\mathrm{IACC}_{\mathrm{E}}\right.$ ) is related to the subjective perception of audio space. The following three categories of building space quality have been defined based on the IACC $_{\mathrm{E} 3}$ value (Hidaka et al. 1995: 989; Table 2):

Table 2. Qualitative division of music spaces according to the $\mathrm{IACC}_{\mathrm{E} 3}$ value.

\begin{tabular}{lcc}
\hline Category & IACC $_{\mathrm{E} 3}$ & 1-IACC $_{\mathrm{E} 3}$ \\
\hline Excellent to exceptional & $0.28-0.38$ & $0.62-0.72$ \\
Good to excellent & $0.39-0.54$ & $0.46-0.61$ \\
Average to good & $0.55-0.59$ & $0.41-0.45$ \\
\hline
\end{tabular}

- bass ratio (BR). Beranek (1996: 428-30) considers prominent bass reflections to be one of the main factors determining the quality of concert halls. At the same time, he determines recommended $\mathrm{BR}$ values for spaces with the reverberation time of $\geqslant 2.3 \mathrm{~s}$ in the range from 1.10 to 1.25 and for the reverberation time of $<1.8 \mathrm{~s}$ in the range from 1.10 to 1.45 ;

- the power of sound $(\mathrm{G})$ indicates the subjectively perceived sound level in space.

The recommendation of ideal values for C80, (1-IACC $\mathrm{E}$ ) and BR parameters applies to the conditions of a fully occupied concert hall. Most measurements are, however, done in (C) Antiquity Publications Ltd. 


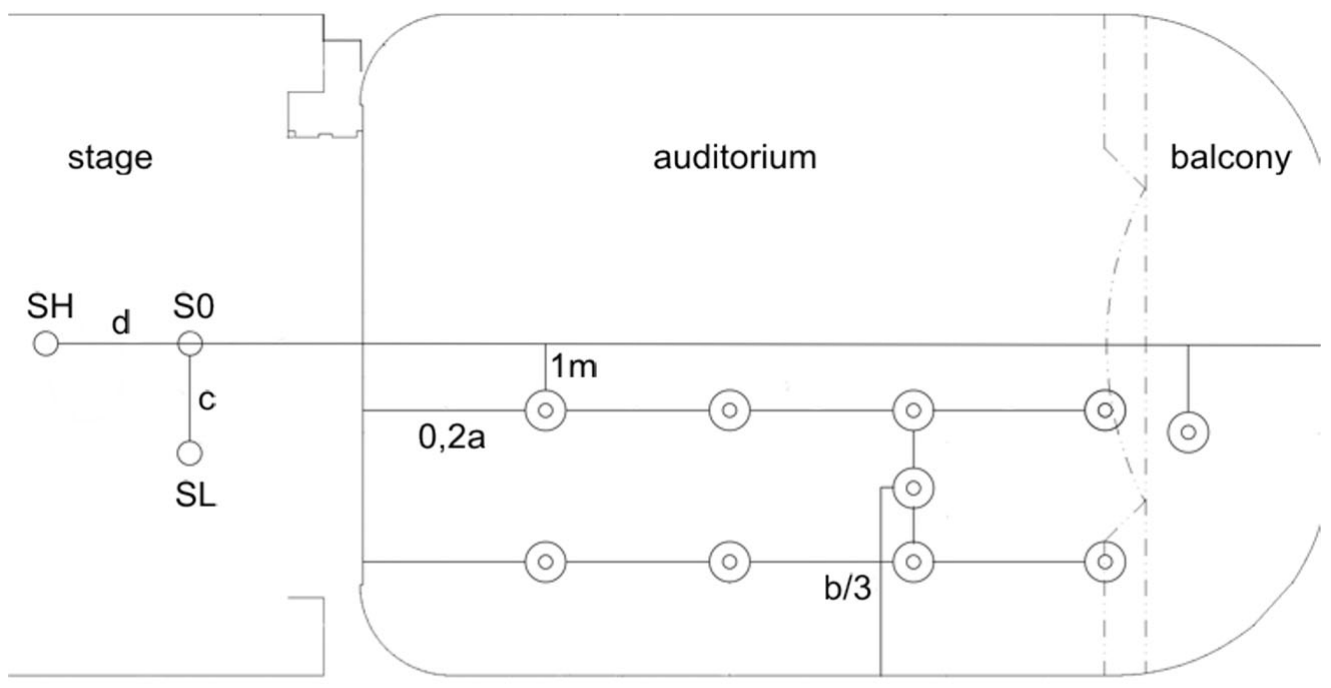

So, SH, SL - sound source positions

(O) - microphone positions

Figure 1. Microphone and sound source placement based on Takenaka R\&́D Institute methodology (Hidaka et al. 1995).

unoccupied spaces, although there are methodologies to simulate a fully occupied space (Nishihara et al. 2001).

\section{Symmetric and asymmetric spaces}

Most of the historic spaces designed for musical and theatrical production can be described as symmetrically constructed, and the best-known methodology for measuring these spaces was compiled by the Takenaka R\&D Institute (Hidaka et al. 1995: 1003). As an example, I cite the distribution of microphones and sound source according to the above methodology, which was used in the research (Brezina 2011) to measure the oldest theatre in Slovakia-the Empire Theatre of Hlohovec (Figure 1). In the case of asymmetric spaces, the measurement must be realised in various positions throughout the whole space. In all cases, however, an omni-directional dodecahedron-shaped sound source and omnidirectional measurement microphones placed at the ear level of a seated listener should be used for the measurement. In each position, it is necessary to perform at least ten repeated measurements, which are then averaged to ensure the greatest accuracy possible. To measure the interaural crosscorrelation coefficient (IACC) a dummy head is used, but the ISO 3382 Standard allows, under certain circumstances, the use of a real head too. The measured values of acoustic space are subsequently evaluated in graphs and tables as described in the Standard. The agreement to use a unified measurement methodology is, in terms of acoustics as intangible cultural heritage, the basic starting point of social acceptance.

(C) Antiquity Publications Ltd. 


\section{Acoustic model creation methodology}

The purpose of creating acoustic models of important historic and cultural monuments is for practical use and for preserving space as intangible cultural heritage in the event that the space does not exist for any reason in the future. As previously mentioned, there are two approaches to creating acoustic models-by impulse response and by virtual modeling. As virtual modelling is not currently applied in practice, I focus on the impulse response method; there are many software manufacturers of reverberation devices using just this method (Audio Ease, Waves, SIR, Freeverb, etc.). The question is for which of the platforms do we create acoustic models, as each platform has its own methodology for creating impulse responses. The fact that the most sophisticated convolution reverb solutions are not freeware and that they require an initial investment in software also plays an important role. The ideal case would be the existence of a high-quality, freeware convolution reverb whose development is funded by grant projects. Today, however, one may consider only the three best quality reverb devices-Audio Ease Altiverb, Waves IR1 and Knufinke SIR 3. Similarly, it is necessary to consider the format in which acoustic models are developed. Typically, stereo is the most widely used format, but lately more and more emphasis is placed on multi-channel sound, as all of the aforementioned reverb devices can create and work with multi-channel impulse responses. As a starting point for stereophonic acoustic space models, we may take advantage of the Audio Ease methodology (Audio Ease 2006), which is the most sophisticated of those examined. For the purpose of creating multi-channel acoustic space models in the past, a four-channel B-format method was applied (Farina $\&$ Ugolotti 1998) and was later perfected by combining several support methods (Farina \& Ayalon 2003: 13). This methodology is also used to create acoustic models for the Waves IR1 convolution reverb.

\section{Acoustics as intangible cultural heritage}

I consider it necessary to unite the outcomes of acoustic space measurement as well as the created acoustic models in a common international database. In this case, I consider the ideal form would be an internet virtual library, where all measured spaces can be searched by period of existence, architectural style, geographical location, function and any other criteria. I propose that each space contain the following information and parts:

- history of the space as a building or its archaeological description, building dimensions and building materials used;

- characteristics of the acoustic space of selected parameters according to the ISO 3382 Standard;

- acoustic space model in a stereo and multi-channel format (for commonly used convolution reverbs);

- audio recordings comparing the real acoustics of space with the model based on the identical audio material.

Based on the above categories, we can talk about a comprehensive database of acoustic spaces that thus achieves the dimension of intangible cultural heritage. Based on my acoustic

(C) Antiquity Publications Ltd. 
research in 2010 and 2011, I began to publish the measurement outputs and acoustic models of important cultural monuments online at http://www.obnova.sk/ (Brezina 2011, 2012). In the database the data is available in the form of graphs, tables, sound samples and acoustic models of spaces.

\section{Conclusion}

The examination of the acoustics of the world's significant cultural monuments is of tremendous importance for exploring historical and cultural contexts, especially in terms of musical or theatrical production. Also important is the fact that precise measurements can contribute significantly to reconstructing or rebuilding premises in the future. For premises that are not easily accessible or in which, for some reason, audio recording cannot be realised, the possibility of creating acoustic models is extremely useful. Combining all of these factors, there is a new dimension of intangible cultural heritage, merging the science of acoustics, architecture, archeology and historiography. The essence of research results should therefore be their availability to the general public, from historians, architects, archaeologists and civil engineers to musicians, sound masters and all those interested in issues of acoustic space. This article aims to highlight the need to discuss ways of consolidating the rules and methodologies for measuring and preserving acoustics inasmuch as there are many diverse approaches. Partial efforts and acoustic research databases in most cases no longer exist, as stated in the introduction of this article. The creation of an international database of acoustic measurements and space models requires, in many cases, a transnational cooperation of institutions, specialised university departments and a specialised public. I believe that a project of this magnitude is feasible and the first step is simply the professional discussion of the issue.

\section{References}

Audio Ease. 2006. Making impulse responses from real acoustic environments for music production. Available at: http://www.audioease.com/Pages/ Altiverb/sampling/Making\%20IR\%27s\%20for\% 20music.pdf (accessed 20 July 2012).

Ben-Hador, R. \& I. NeOran. 2004. Capturing manipulation and reproduction of sampled acoustic impulse responses. Paper presented at the $117^{\text {th }}$ AES Convention, San Francisco, 28-31 October 2004.

BERANEK, L. 1996. Concert and opera halls: how they sound. New York: Woodbury.

BreziNA, P. 2011. Akustický model neskororománskej kaplnky Nitrianskeho hradu. Obnova. Available at: http://www.obnova.sk/blog/akusticky-modelneskororomanskej-kaplnky-nitrianskeho-hradu (accessed 20 July 2012).

- 2012. Akustické vlastnosti Empírového divadla v Hlohovci. Obnova. Available at: http://www.obnova.sk/blog/akustick\%C3\%BDmodel-emp\%C3\%ADrov\%C3\%A9ho-divadla-vhlohovci (accessed 20 July 2012).
FARINA, A. \& R. AYALON. 2003. Recording concert hall acoustics for posterity, in AES (ed.) Proceedings of the AES $24^{\text {th }}$ International Conference: Multichannel Audio, The New Reality, Banff, Alberta, Canada, 2003 June 26-28:1-14. New York: AES. Available at: http://pcfarina.eng.unipr.it/Public/Papers/185AES24.PDF (accessed 20 July 2012).

Farina, A. \& E. UgOLOTTI. 1998. Software implementation of B-format encoding and decoding. Paper presented at the $104^{\text {th }}$ AES Convention, Amsterdam, May 16-19 1998. Available at: http://www.ramsete.com/Public/ Papers/109-AES98.PDF (accessed 20 July 2012).

GERZON, M. 1975. Recording concert hall acoustics for posterity. Journal of the Acoustical Society of America 23: 569 .

HADDAD, N.A. 2008. Reviving the architectural and acoustical theatre heritage: the role of ERATO Project, in CSAAR (ed.) The Fifth International Conference of the Center for the Study of Architecture in the Arab Region (CSAAR 2008B): responsibilities and opportunities in architectural conservation: theory, education, and practice 3-5: 421-34. Amman: CSAAR. 
HidAKA, J., L. BERANEK \& T. OKANO. 1995. Interaural cross-correlation, lateral fraction, and low- and high-frequency sound levels as measures of acoustical quality in concert halls. Journal of the Acoustical Society of America 98: 988-1007.

KarabiBER, Z. 2002. The conservation of acoustical heritage, in Proceedings of the First International Workshop on 3D Virtual Heritage, Geneva, 2-3 October, 2002: 286-90. Available at: http://www.cyf-kr.edu.pl/ ncbratas/pdf/ full_karabiber.pdf (accessed 20 July 2012).

KNIGHT, J.D. 2010. The archaeoacoustics of San Vitale, Ravenna. Unpublished $\mathrm{PhD}$ dissertation, University of Southampton.

MORGAN, M. 1960. Vitruvius: the ten books on architecture. New York: Dover.

MurPhy, D.T. 2005. Multi-channel impulse response measurement, analysis and rendering in archaeological acoustics. Paper presented at the $119^{\text {th }}$ AES Convention, New York, 7-10 October 2005.

- 2006. Archaeological acoustic space measurement for convolution reverbation and auralization applications, in $9^{\text {th }}$ International Conference on Digital Audio Effects (DAFx-06), Montreal, Canada, September 18-20 2006: 221-26. Montreal: McGill University. Available at: http://www.dafx.ca/ proceedings/papers/p_221.pdf (accessed 21 July 2012).

NishiHARA, N., T. HidAKA \& L. BERANEK. 2001. Mechanism of sound absorption by seated audience in halls. Journal of the Acoustical Society of America 110: 2398-411.
SAVIOJA, L., J. HuOPANIEMI, T. LOKKI \& R. VÄÄNÄNEN. 1999. Interactive virtual acoustic environments. Journal of the Acoustical Society of America 47: 675-705.

SCARre, C. \& G. LAWSON (ed.). 2006. Archaeoacoustics. Cambridge: McDonald Institute for Archaeological Research.

SUTN Slovenský ústav technickej normalizácie. 2010. STN EN ISO 3382-1 Acoustics. Measurement of room acoustic parameters. Part 1: performance spaces. Bratislava: Slovak Office of Standards, Metrology and Testing.

VONDrÁšEK, M. \& M. ANTEK. 2005. Comparison of objective criteria of concert halls quality. Acoustic Letters 11: 9-18.

VondrášEK, M., M. Mikeš \& R. FleisChman. 2008. Acoustics of music spaces in the Czech Republic. Prague: AMU.

- 2010a. Acoustics of music spaces in the Czech Republic 2. Prague: AMU.

- 2010b. Acoustics of music spaces in the Czech Republic 3. Prague: AMU.

- 2011. Acoustics of music spaces in the Czech Republic 4. Prague: AMU.

Watson A. \& D. KeAting. 1999. Architecture and sound: an acoustic analysis of megalithic monuments in prehistoric Britain. Antiquity 73: 325-36.

YRP The York Renaissance Project. n.d. Available at: http://www.renaissanceyork.org.uk/ (accessed 21 July 2012).

Received: 24 July 2012; Accepted: 9 August 2012; Revised: 9 August 2012

(C) Antiquity Publications Ltd. 